\title{
Socio-economic determinants for industry development: the case of Australia's Sydney rock oyster industry
}

\author{
Peggy SchrobBack ${ }^{1, a}$, Louisa CoGlan ${ }^{1}$ and Sean PAScoE ${ }^{2}$ \\ 1 School of Economics and Finance, Queensland University of Technology, GPO Box 2434, Brisbane, QLD 4001, Australia \\ ${ }^{2}$ CSIRO, Oceans and Atmosphere Flagship, EcoSciences Precinct, PO Box 2583, Brisbane, QLD 4001, Australia
}

Received 6 November 2014; Accepted 8 December 2014

\begin{abstract}
Socio-economic characteristics such as age, gender, educational attainment, employment status, and income contain vital information about how an industry may respond to changing circumstances, and hence are of importance to decision makers. While some socio-economic studies exist, relatively little attention has been given to fishery and aquaculture industries in regards to their socio-economic profiles and their role in the development prospects of these industries. In this study, by way of example, we focus on Australia's Sydney rock oyster (Saccostrea glomerata) (SRO) industry. The aim of this study was identify the socio-economic profile of the SRO industry and to illustrate the value of such information for an industry management assessment. The SRO industry has experienced a major decrease in production volume since the late 1970 and continues to be affected by prevailing diseases and increasing market competition from Australia's Pacific oyster (Crassostrea gigas) industry. It is likely that socio-economic aspects have influenced this development within the SRO industry. The socio-economic profile was developed using data from a SRO industry farm survey which was undertaken in 2012. Findings suggested that this industry is characterised by a mature aged oyster farmer population and a part-time oyster farming approach. These characteristics may affect the farmers' ability to drive innovation and growth. The results also suggested that there may be potential industry entry barriers present in the SRO industry which may prevent younger people taking up oyster farming. Given the results, the study concluded that the current socio-economic profile of the industry has likely contributed to the present economic status quo of the industry.
\end{abstract}

Keywords: Socio-economic profile / demographics / industry development / aquaculture / Sydney rock oyster industry / Saccostrea glomerata

\section{Introduction}

Socio-economic characteristics such as age, gender, educational attainment, employment status, and income have been shown to be major factors affecting behaviour of individuals in a wide range of industries, including fisheries and aquaculture (e.g., Tzanatos et al. 2006; Pascoe et al. 2014). These characteristics can shape the development of an industry as well as its response to external drivers, including environmental, economic and policy drivers. Consequently, investigating the socio-economic profile of fishers and aquaculturists can potentially provide important insight into the industry structures and issues, and thus may offer a bases for modifications to the industry management.

This study, by way of example, focused on Australia's Sydney rock oyster (Saccostrea glomerata) (SRO) industry. The SRO is a native species in Australia that has been cultivated commercially for about 130 years (Schrobback et al. 2014). Production areas of the industry are located in estuaries

a Corresponding author: p.schrobback@gmail.com along the New South Wales (NSW) and south-east Queensland (QLD) coasts (Fig. 1). The industry has been faced with a range of challenges, particularly since the late 1970s. Issues include for example the management of prevailing diseases, water quality impairments from increasing coastal development and increasing market competition from Australia's Pacific oyster industry. This has lead to a decline in SRO production value from about 9250 tons in 1980 to 4500 tons in 2012 (Schrobback et al. 2014). A detailed summary about the history and status quo of the SRO industry has been provided by Schrobback et al. (2014).

It is likely that socio-economic characteristics of industry members have had an influence on the current situation of the SRO industry. However, a longitudinal data survey about the socio-economic profile of the industry has not been undertaken.

The aim of this study was to develop a socio-economic profile of the SRO industry and to illustrate the value of socioeconomic information about industry members for an assessment of current industry management strategies. The following research questions were investigated: Who are SRO growers? 


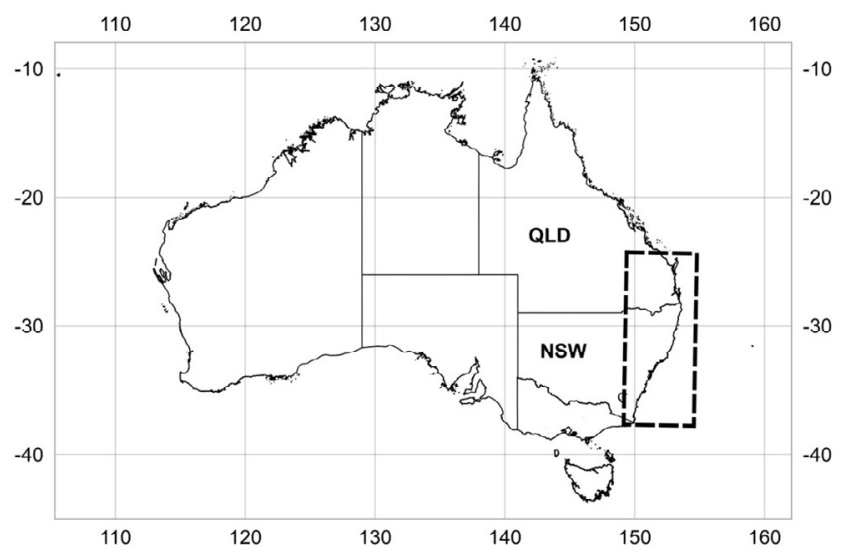

Fig. 1. Sydney rock oyster (SRO) production regions in Australia in New South Wales (NSW) and Queensland (QLD).

Are SRO farmers different from other population cohorts in Australia? What are oyster farmer's perceptions on the status quo and future of the industry? What is the potential role of oyster grower's characteristics in the industry's current economic performance?

The socio-economic profile presented in this study was developed based on data from a SRO industry farm survey which was undertaken in 2012. This study did not only examine demographic and economic characteristics of oyster growers, it also collected information about farmer's opinion about the prospects of the industry and issues that they believe affect the industry's current performance. In the absence of a similar profile for comparable fishery and aquaculture industries in Australia and worldwide, the findings from the survey were compared to other Australian population cohorts where appropriate. The results and their implications for the industry management were discussed. The findings of the study may be of interest for stakeholders of other fisheries and aquaculture industries who are dealing with similar challenges as the SRO industry.

\section{Methodology and data}

The data for a socio-economic analysis were obtained from an oyster farm survey which was conducted among oyster farmers from QLD and NSW during July to November 2012. The survey was undertaken as a mail survey. This surveying technique was chosen since the industry management advised the project team that an online survey would not be appropriate for targeted participants due to most oyster farmers' limited information technology (IT) proficiency.

Mail surveys are known to have a relatively low response rate if potential participants are contacted without any preexisting awareness of the study (Jobber and O'Reilly 1996). Therefore, a meeting with the QLD oyster farming group was conducted in the lead-up to the mailing and information about the survey was distributed in an industry newsletters to oyster farmers in NSW prior to conducting the mail survey. A draft of the survey was sent to the industry management and selected oyster farmer representatives for comments on the design and clarity of questions.
The survey was aimed at collecting information about a range of aspects related to oyster production, such as oyster area, farming practices and stock maintenance, farming inputs (e.g., asset types and values) and outputs (e.g., quantity of different oyster grades), sale information, environmental issues, perceived restrictions to expansion of production, and personal information about oyster farmers. All data collected referred to the production year 2011/12.

Oyster farming in Australia is a regulated activity, thus, it was possible to determine the exact number of permit holders within the industry. In 2012, the SRO industry was comprised of 394 registered farm businesses (permit holders) located in NSW and QLD. All registered oyster businesses were approached by mailing the survey with the assistance of key State regulatory institutions, the New South Wales Department of Primary Industries and the Queensland Department of Agriculture, Fisheries and Forestry, which hold confidential contact details of all oyster farmers in the respective State. A reminder to participate in the study, which included an additional copy of the survey document, was sent out to the oyster farmers two months after the first mailing took place.

Sixteen per cent of all oyster growers responded to the survey. If contact details were provided by the survey participants, a follow-up telephone interview was undertaken in cases where clarifications on the responses were required. Responses from 3 oyster farmers in NSW, who were involved in growing Pacific oysters, were eliminated from the analysis as the focus of the study is on the SRO growers only. After digitalising and cleaning of the data, 53 surveys (24 from QLD and 29 from NSW) representing $13.5 \%$ of the reference population provided an appropriate level of information to develop a socio-economic profile of the industry. This distribution of survey responses does not represent the spatial allocation of production volume which is important to be considered in the interpretation of results.

The response to the survey categories oyster area information, farming practices and stock maintenance, farming inputs and outputs provided insufficient information and was inappropriate for any type of economic analysis.

\section{Results}

The results from the survey show that the majority of oyster farmers in the sample were male (Table 1). Only $11 \%$ of oyster growers were female. The vast majority of the surveyed oyster growers were born in Australia and only 2\% in New Zealand.

The median age of oyster farmers in the sample was 56.0 years. QLD oyster growers appeared to be slightly older than farmers in NSW, with a median age of 56.5 years and 51.5 years, respectively (Table 1 ).

The household composition of all oyster farmers in the sample indicates that there were on average 2.4 people living in their home (Table 1). However, there appears to be a slight difference in the household size between the two States, as QLD oyster farmers seem to have had less people living in their household than NSW oyster farmers (Table 1). A similar result was found for the number of children of oyster farmers 


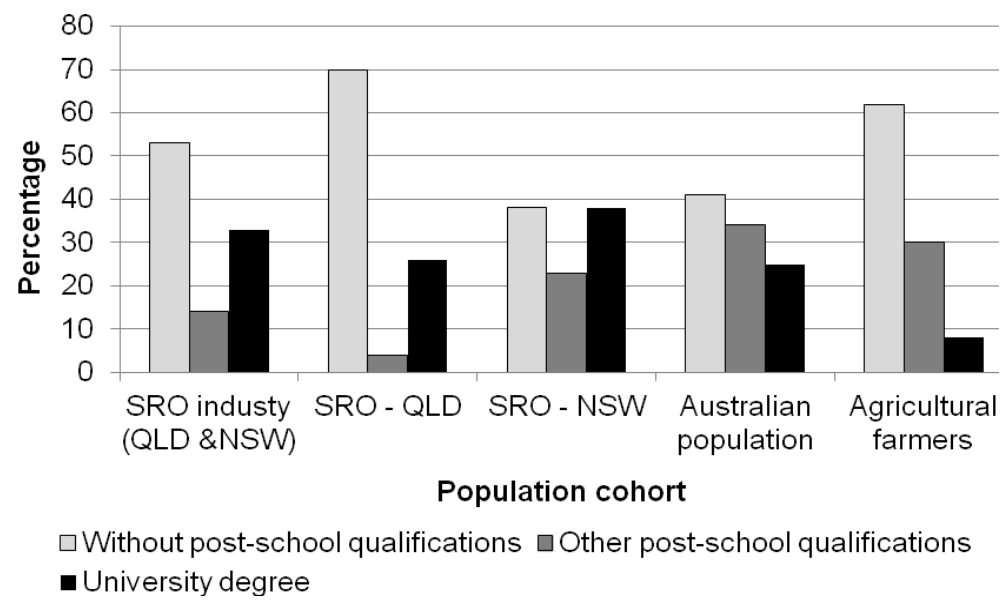

Fig. 2. Educational attainment of SRO industry and other population cohorts. Without post-school qualification includes 12 or less years of schooling, other post-school qualifications includes 12 years of schooling and additional vocational training (e.g., certificates, diplomas), university degree includes bachelor degrees or post-graduate qualifications. Sources: Australian population statistics (includes people aged 15-64 years) from ABS (2012b), Australian agricultural farmer statistics from ABS (2012a).

Table 1. Demographic information.

\begin{tabular}{lccc}
\hline Demographic characteristics & QLD & NSW & TOTAL \\
\hline Gender & & & \\
\hline Female & $16.7 \%$ & $6.9 \%$ & $11.3 \%$ \\
Male & $83.3 \%$ & $93.1 \%$ & $88.7 \%$ \\
\hline Country of birth & & & \\
\hline Australia & $95.8 \%$ & $100.0 \%$ & $98.0 \%$ \\
New Zealand & $4.2 \%$ & $0.0 \%$ & $2.0 \%$ \\
Other & $0.0 \%$ & $0.0 \%$ & $0.0 \%$ \\
\hline Age & & & \\
\hline Minimum & 29.0 & 25.0 & 25.0 \\
First quartile & 51.0 & 38.0 & 49.0 \\
Average & 57.5 & 49.1 & 54.5 \\
Median & 56.5 & 51.5 & 56.0 \\
Third quartile & 65.0 & 59.0 & 62.0 \\
Maximum & 76.0 & 69.0 & 76.0 \\
\hline Household & & & \\
\hline Number of children & 2.2 & 2.5 & 2.4 \\
Number of people living & 2.1 & 2.7 & 2.4 \\
in household & & & \\
\hline
\end{tabular}

in the sample. QLD growers appeared to have fewer children than NSW farmers.

Figure 2 illustrates a summary of the educational attainment of SRO farmers in the sample and other population cohorts. The level of educational achievement within the group of all oyster growers in the sample shows that about $53 \%$ of farmers had no formal post-school qualifications. About $15 \%$ of farmers stated that they obtained a post-school qualification which may include, for example, a vocational training. Approximately, $33 \%$ of oyster growers reported to have obtained a university degree.

Growers in QLD likely had a slightly lower educational qualification than oyster farmers in NSW (Fig. 2). However, the share of farmers who obtained a tertiary degree is for both oyster grower sample sub-cohorts relatively high with $26 \%$ of QLD and 38\% for NSW. The members of the SRO industry appeared to have a similar educational attainment level as the
Table 2. Experience of oyster farmers.

\begin{tabular}{lccc}
\hline Experience of farmers & QLD & NSW & TOTAL \\
\hline Years in the industry & & & \\
\hline Minimum & 0.0 & 1.0 & 0.0 \\
First quartile & 4.0 & 6.0 & 5.0 \\
Mean & 14.5 & 20.2 & 15.9 \\
Median & 10.0 & 19.0 & 10.0 \\
Third quartile & 28.0 & 35.0 & 25.0 \\
Maximum & 50.0 & 50.0 & 50.0 \\
\hline Inter-generational experience & & & \\
\hline Farmers in first family generation & $83.3 \%$ & $60.7 \%$ & $71.2 \%$ \\
$\begin{array}{l}\text { in oyster farming } \\
\text { Maximum number of family } \\
\text { generations }\end{array}$ & 4.0 & 6.0 & 6.0 \\
\hline Association, capacity building, other & & & \\
\hline $\begin{array}{l}\text { Member in oyster farming association } \\
\text { Attendance of training or workshops } \\
\text { in the past year }\end{array}$ & $41.7 \%$ & $58.6 \%$ & $50.9 \%$ \\
$\begin{array}{l}\text { Experience with other fish / shellfish } \\
\text { species }\end{array}$ & $12.5 \%$ & $27.6 \%$ & $20.8 \%$ \\
\hline
\end{tabular}

Australian population and a higher educational level than agricultural farmers (Fig. 2).

A large proportion of the surveyed oyster farmers in the sample had a household income of up to 40000 Australian dollars per annum (Fig. 3). The distribution of household income patterns in QLD was similar to the one in NSW, although QLD appeared to have a slightly higher share of households earnings in the 80000-100000 Australian dollars income bracket (Fig. 3) However, this observation may be attributed to a sampling bias.

The surveyed oyster growers also reported that a large proportion of their household income is obtained from off-farm activities. The proportion of their total annual income from oyster framing is shown in Figure 4.

A large number of oyster farmers in the sample with an annual income of over 40000 Australian dollars received less that $25 \%$ of their income from oyster farming (Fig. 4). Farmers 


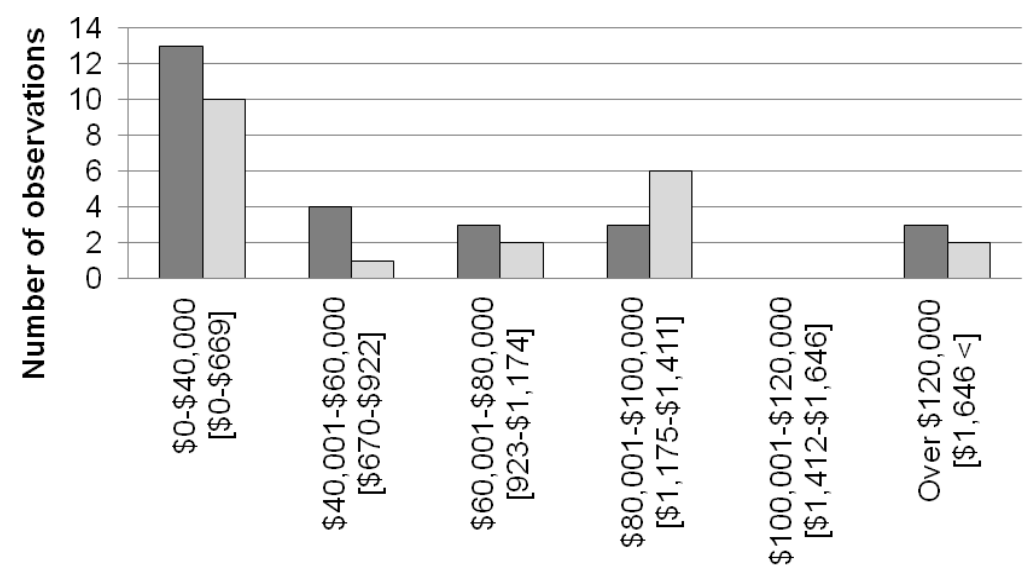

Annual income [ weekly disposable income ]

(Australian Dollars)

$\square$ NSW farmers in the income bracket $\square$ QLD farmers in the income bracket

Fig. 3. Household income distribution for SRO industry. Weekly disposable income (net income) estimates for income brackets derived from Australian Taxation Office (2013).

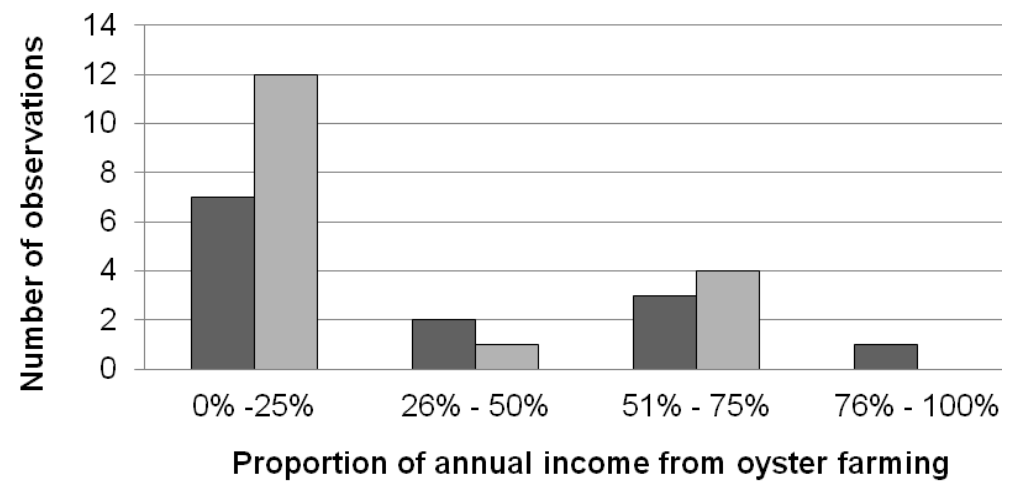

Annual income $<\$ 40,000 \quad \square$ Annual income $>\$ 40,000$

Fig. 4. Proportion of annual income from oyster farming (all values in Australian dollars).

with an income less than 40000 Australian dollar per annum appeared to receive similar proportions of their total income from oyster farming as higher income oyster farmers. While, only a small number of farmers with a total income of up to 40000 Australian dollars per annum obtained the majority of their income from oyster farming, no farmers of the higher income brackets seem to have received more than $75 \%$ of their annual earnings from oyster farming.

The surveyed SRO growers had on average 15.9 years experience in the industry, ranging from less than 1 year to 50 years (Table 2 ). No experience suggests that survey respondents had entered the industry within 12 months before the survey was conducted. On the other hand, 50 years of experience in the industry implies that some farmers had worked in the industries their entire life. The average level of experience in oyster farming varied between both States, with NSW growers having acquired more expertise in the industry than QLD growers.

The representation of the results for oyster farmer's age against the year of entry to the industry shows that most of the farmers in the sample entered the industry during 1995 to 2010 (Fig. 5). The illustration also indicates that a large proportion of oyster farmers were at entry to the industry over 40 years of age. The number of farmers entering the industry under the age of 35 in the period between 1960s and 1990s was relative high but decreased in the past two decades.

The proportion of farmers with less than 15 years of experience in oyster farming was particularly high in the age group of 40 to 60 year old oyster farmers (Fig. 6).

The vast majority of the surveyed oyster farmers were the first generation of oyster growers in their families (Table 2). Yet, some businesses were run by the 6th generation of oyster farmers in their family.

About $68 \%$ of all oyster growers in the sample were a member in an oyster farming association and about $51 \%$ of farmers attended a training or workshop in the past year (Table 2). Only $21 \%$ of growers had experience in cultivating other fish or shellfish species (Table 2).

Survey participants were asked about their perception of the development prospects of the SRO industry. The responses 


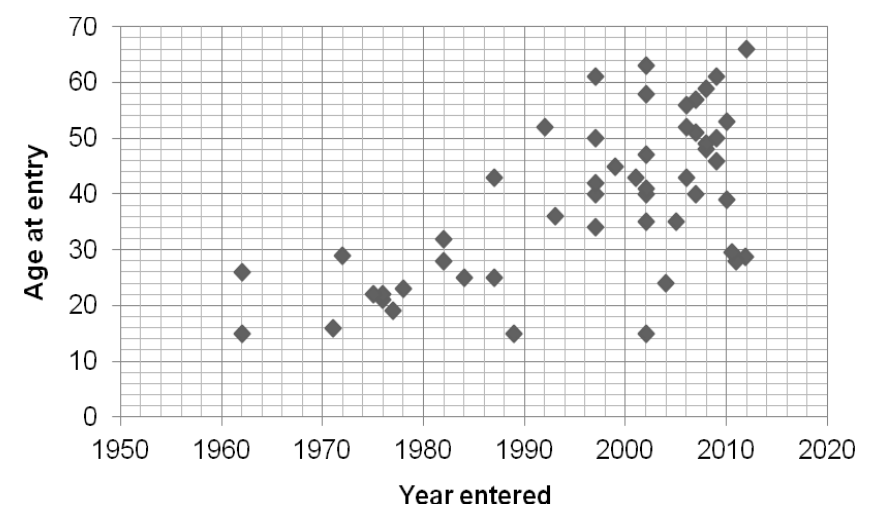

Fig. 5. Oyster farmer's age at entry to the industry.

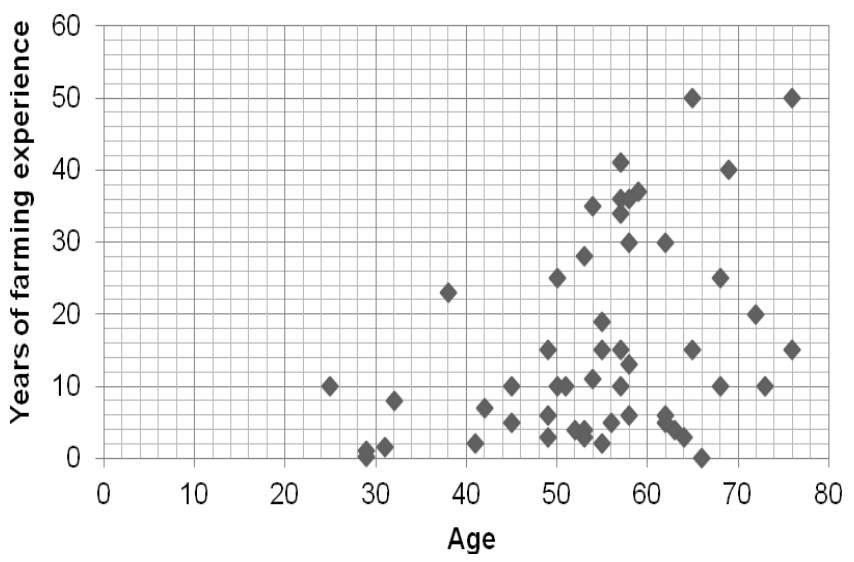

Fig. 6. Years of farming experience against farmer's age.

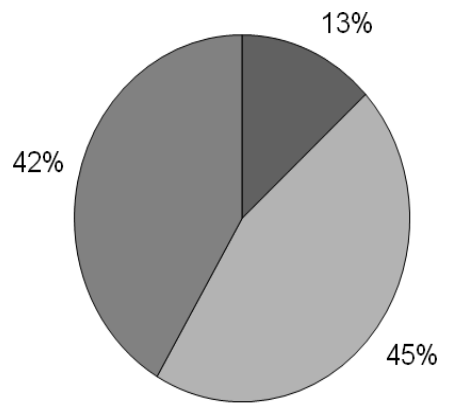

$\square$ Positive $\square$ Negative $\square$ Neither

Fig. 7. Oyster farmer perception on industry prospects.

were categorised into positive, negative and neutral attitudes. Although about $42 \%$ of responses indicated neither positive nor negative opinions about the future development prospects, almost half of all oyster growers were pessimistic about the industry's future (Fig. 7). Farmers with a negative view about the future of the industry clearly outnumbered people with a positive outlook, which was stated by only $13 \%$ of participants (Fig. 7).

Issues affecting the future development of the industry that were raised included increasing production costs (e.g., fees and charges for water and shellfish sampling and permits), limited product promotion/marketing scope, lack of assistance from
Table 3. Responses to specific issues of the industry. Percentage of responses that rate the category as issue (includes "Agree" and "Strongly Agree").

\begin{tabular}{lc}
\hline Issue category & Responses (\%) \\
\hline Availability of seed & 45.2 \\
Cost of seed & 41.3 \\
Availability of leased land & 37.2 \\
Availability of oyster areas & 26.8 \\
Lack of markets / low product prices & 65.1 \\
Problems with predators & 62.8 \\
Problems with diseases & 64.3 \\
Inadequate water quality & 35.0 \\
Stock theft & 68.3 \\
Lack of training & 17.1 \\
Lack of cooperation among oyster farmers & 35.0 \\
in the region & \\
Ineffective bodies to support in supporting & 54.8 \\
oyster farming & \\
Inappropriate emergency response strategies & 43.6 \\
\hline
\end{tabular}

government institutions, low product price, competition from the Pacific oyster industry and the very wet weather conditions in NSW in 2011/12 (see Appendix). Some survey participants identified export of oysters as a potential to expand the industry's current market range and ultimately its profitability. Selected responses from oyster growers about the prospects of the industry can be found in the Appendix.

When asked about specific issues that affect the industry, about $68 \%$ of all survey respondents agreed or strongly agreed that stock theft is an issue, followed by $65 \%$ of participants who indicated that there is a lack of market or that a low product price poses an issue for their business (Table 3). Problems with diseases and predators were also identified as major issues with 63 and $64 \%$ of respondents agreeing or strongly agreeing, respectively. About half of the farmers in the survey believed that industry bodies were ineffective in supporting oyster farming. Less problematic for industry members appeared to be the availability of oyster areas (27\%) and seed (45\%) as well as hatchery seed costs $(41 \%)$. Adequate water quality $(35 \%)$, the lack of training $(17 \%)$ and cooperation among farmers $(35 \%)$ were rated among the least challenging matters for the industry.

In the survey, participants were asked to indicate whether they would diversify their current production of SROs by introducing varieties Pacific oysters (Crassostrea gigas) (wild and/or triploid) if State regulation would permit that. The results show that the industry overall was much divided about the introduction of Pacific oyster varieties. However, QLD growers appeared to be slightly more in favour of introducing Pacific oysters than NSW growers (Fig. 8).

\section{Discussion}

The purpose of this study is to develop a socio-economic profile of the SRO industry. The results from the farm survey show that the SRO industry is male dominated which is not untypical for primary industries (Productivity Commission 2005). The analysis of survey data revealed that only $11 \%$ 


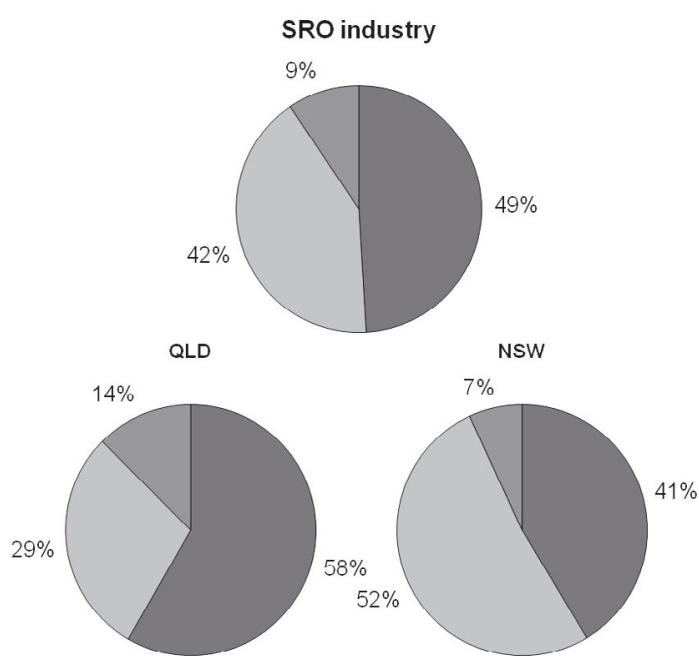

$\square$ Agreement $\quad \square$ Disagreement $\square$ Nocomment

Fig. 8. Farmer opinion about the introduction of Pacific oysters.

of SRO farmers were women. This is less than the proportion of women engaged in agricultural farming in Australia (28 per cent) (ABS 2012a). The very physical work involved in oyster farming is a likely reason why the majority of oyster farmers are male. The relatively low number of female oyster growers in this industry could also be culturally motivated. However, several survey respondents mentioned in follow-up phone interviews that their wives are engaged to some degree in the oyster business, e.g., accounting or other part-time paid or unpaid farm support work.

The majority of SRO farmer's country of origin is Australia. This suggests that the cultural and ethnical background of oyster farmers is less diverse than the rest of Australia's population (about 30\% of Australia's population was born overseas) (ABS 2013a). The commonly used marketing slogan 'Australian owned' can incontestably be applied to products offered by this industry.

The findings from the survey also show that the SRO industry is dealing with an aging farmer population. A similar trend has been observed for Australian agricultural farmers (Productivity Commission 2005; ABS 2012a). Yet, oyster farmers are likely even older than agricultural farmers in Australia. While the median age of agricultural farmers was 53 in 2011 (ABS 2012a), SRO oyster farmer's median age exceeded that age by three years (Table 1). Furthermore, oyster farmers are also considerably older than workers in other professions in Australia, whose median age was 40 years in 2011 (ABS 2012a).

Farmers in NSW are likely to have slightly more children than QLD oyster farmers. The oyster growers in QLD are more likely to live smaller households than NSW growers. The slightly lower median age of NSW growers and their larger household size compared to QLD growers suggests that children may still be part of their households.

SRO farmers show on average a similar level of educational qualification compared to Australia's total population (ABS 2012b) and a higher educational level than Australia's agricultural farmers (ABS 2012a) (Fig. 2). Given that the combined proportion of farmers with post-school and tertiary degrees is higher in NSW than in QLD, NSW growers are likely to have a higher educational level than QLD growers. The farmers in NSW may have obtained a higher level of academic qualification than Australia's total population. However, this finding may be likely due to a sampling bias and should be interpreted with caution.

The very high proportion of growers without post-school qualifications in QLD may be explained by the older age of farmers in this production region. The proportion of individuals without post-school qualifications is currently lower in higher age groups in Australia (ABS 2012b) and most likely reflects a lack of access to further educational training for these age groups, historically. Another likely reason for the higher degree of qualification amongst NSW farmers compared to their counterparts in QLD may be linked to the differing scale of production in these regions, which is generally higher in NSW than in QLD. With increasing production scale, aquaculture farm businesses are becoming increasingly complex. Thus, large-scale oyster farmers may need to be more educated than traditional farmers and more qualified as managers with the same skill and responsibility as any business managers (based on Cary et al. 2002).

The majority of oyster farmers reported a disposable income of less than 669 Australian dollars per week (or up to 40000 Australian dollars annually) (Fig. 2). Compared to income statistics for all Australian households most oyster grower can be categorised as low income households ${ }^{1}$. Comparable Australian population cohorts in terms of age appear to have a higher weekly disposable income than the majority of oyster farmers. For example, in 2011-2012 a couple (older than 35 and younger than 55) with dependent children (aged between 15-24 years) had a mean household income of 873 Australian dollars per week and a couple aged 55 to 64 years with no children received a mean disposable income of 1044 Australian dollars per week (ABS 2013b). Furthermore, the mean disposable household income of all households in Australia in 2011-2012 was 918 Australian dollars per week (ABS 2013b), which is higher than the weekly income of oyster farmers. In contrast to that, the weekly income of Australian agricultural farmers was 568 Australian dollars during the same period which is lower than what we found for oyster growers (ABS 2012a) ${ }^{2}$. It can be concluded that SRO farmers and Australian agricultural farmers belong to the same low household income category as defined by the Australian Bureau of Statistics (ABS 2013b).

This study further found that a low proportion of the farmer's household income is generated by their oyster business (Fig. 4). This suggests that SRO farming is a part-time activity for a large proportion of farmers and that household income of most people engaged in SRO farming is obtained

\footnotetext{
${ }^{1}$ Lowest threshold for weekly disposable income of low income households: 475 Australian dollars; lowest threshold for weekly disposable income of middle income households: 793 Australian dollars; lowest threshold for weekly disposable income of high income households: 1814 Australian dollars (ABS 2013b).

${ }^{2}$ We only report the upper threshold of weekly disposable income while Australia agricultural farmer income statistic displays an average value.
} 
from other income generating activities. This finding supports industry statistics showing that a relatively large proportion of oyster farmers produce relatively small quantities of oysters annually (NSW DPI 2003 2013). Unfortunately, the survey did not explore the nature of off-farm activities in further detail.

Although the survey asked participants about production volume, income, costs and farm assets and their value, the number and quality of responses to these questions were insufficient for an analysis. Hence, an investigation into accounting balances, profitability and structure of assets and liabilities of SRO farming businesses such as undertaken by Girard et al. (2014) for oyster farming enterprises of Marennes-Oleron Bay in France could not be conducted.

Since SRO farmers mostly own and manage their businesses it would be difficult to analyse their personal financial circumstances in isolation from the financial arrangements of their oyster farm and other income sources. Losses from farm income are commonly deferred over subsequent production years and profits are often reinvested into the business. Oyster farmers and agricultural farmers are very similar in that regard (ABS 2012a). While oyster farmers may have a low income, it needs to be emphasised that disposable income is only one aspect of farmer's economic well-being. Wealth in form of superannuation, property, shares, and oyster farm assets may be drawn upon to smooth and support household consumption over time, particularly in periods of very low income from oyster farming. Other aspects of economic well-being may include motivation (e.g., way of life, to have independence at work, having greater flexibility for personal/family life, having the power to make own business decisions) and opportunity costs of oyster farmers to work in this primary industry. These aspects could be of importance in order to attract new people to become oyster growers.

The observation that a large proportion of farmers who entered the industry in the last 20 years were of mature age (Fig. 5) suggests that a relatively high number of individuals worked in different professions and chose to become an oyster farmer at pre-retirement age based on life-style decisions. This finding may be supported by the relatively high proportion of farmers with tertiary qualifications that are required in other professions.

Interestingly, the majority of oyster growers appear to be first generation oyster farmers (see Table 2). This indicates that the skill of oyster farming is mainly an acquired skill (at mature age) that is not handed down among family generations. This is particularly the case for Queensland where over $80 \%$ of growers are first generation oyster farmers.

Of particular concern are the very low proportion of young farmers present in the industry and the high proportion of oyster growers older than the official retirement age in Australia (Table 1). This together with the trend towards fewer young people entering the industry (see Fig. 6) may be attributed to increasing well-paid employment alternatives in other industries, such as the mining industry. A similar trend was observed in Australian agricultural farming were the proportion of farmers aged less than 35 years fell from $28 \%$ in 1981 to $13 \%$ in 2011 (ABS 2012a). Another reason that may prevent young people to enter the industry may be the lack of access to capital since financial institutions are generally reluctant to loan against oyster leases due to the high production risks involved. Other factors that may contribute to the skewed age profile of oyster farmers may include: (a) fewer people in total entering the oyster industry; (b) low exit rate at traditional retirement age, due to relatively late entry, and possibly compounded by limited interest of young people in taking over the oyster farms; (c) delayed industry exit decisions in response to reduced farm capital during poor seasons or reduced market value during periods of low market prices (based on Productivity Commission 2005). A more detailed analysis is required to identify potential industry entry barriers and to attract and facilitate the entry of more young people to the industry. The industry is located in rural coast regions where unemployment is higher than in metropolitan regions of Australia (ABS 2013a), thus, options of drawing on this employment situation should be investigated by the industry management.

The present age structure of the industry members, the predominantly small-scale and part-time business approach to oyster farming raises a concern about implications for innovation and the attraction of investment. A previous study about primary industries in Australia concluded that the main limitations to the adoption of new technologies were human capital and knowledge constraints, with farmers not having the necessary skills, incentives or information required for successfully integrating innovations into existing farming systems (Nossal and Sheng 2010). Similar to other primary industries, the SRO industry will remain depended on public investment in research and development irrespective of the age structure of oyster farmers. However, the ability to drive/support the innovation and their translations into industry practise as well as willingness to co-operate with research institutions may likely improve with more young people entering the business.

The important role of producer organisations in fishery industries has recently been investigated by Karadzic et al. 2013). These authors found that fishers perceive and understand their membership experience as important to their capacity to learn from each other. It was also shown that producer organisations affect attitudes towards adaption to change economic and other incentives (e.g., need to belong), rules and trust in leadership (Karadzic et al. 2013). The results from this study show that almost $70 \%$ of all oyster farmers in the survey were members in a farming association (Table 2). These institutions, mainly NSW Farmers and Queensland Oyster Grower Association, provide a representation of the industry, consultation, sharing of information, training and advocacy. The proportion of oyster farmers affiliated with a farming organisation was highest in QLD. This is likely due to the limited spatial distribution of oyster farming in QLD, which is mostly located in or around the Moreton Bay and may offer more opportunity for association. Based on the findings, it can be assumed that social learning, collaboration and collective action within the SRO oyster farmer community is reasonable high. However, this finding does not allow a conclusion about the participation of farmer in industry matters (e.g., farmers contribution to industry development strategies) which appears to be an issue within the SRO industry according to Leith and Haward (2010).

The responses from survey participants also suggested that SRO industry members have a rather pessimistic view about 
the prospects of the industry (Fig. 7). Frustration comes from the decreasing profitability of their businesses due to low product prices and increasing production cost (e.g., food safety compliance costs). Furthermore, increasing severe weather events also appear to cause increasing negative attitudes among farmers. Nevertheless, we also found that farmers are very fond of their products (Appendix).

The sensitive matter of a potential further expansion of areas allocated to wild and triploid Pacific oysters cultivation in NSW and QLD was reflected in the responses of the farmers (Fig. 8 and Appendix). The industry is clearly much divided about this topic which reflects the difficulty for the industry management to respond to economic losses in the SRO industry by employing alternative oyster industry management strategies. A decision to expand areas allocated to wild and triploid Pacific oyster cultivation in NSW and to QLD should be underpinned by scientific and economic research, which allows a full valuation of possible economic, social and environmental trade-offs.

This study was, to knowledge of the authors, the first survey-based investigation into socio-economic situation of the SRO industry. It should be noted, however, that gaps in responses to several sections of the survey limited the array of assessed characteristics. For example, participants were asked about labour input on oyster farms, yet, the number of responses was inappropriate for an analysis. Furthermore, the obtained sample size of 53 oyster farmers is relatively small and may not appropriately reflect all properties of the entire oyster farmer population. Thus, results may be biased. Future surveys on the socio-economic characteristics of farmers should also include questions about farmers' perceptions about industry entry barriers, potential opportunity costs of being an oyster farmer and types of off-farm activities. Due to the lack longitudinal survey data an analysis of possible changes in the profile of SRO farmers could also not be undertaken.

\section{Conclusion}

The aim for this study was to develop a socio-economic profile of the SRO industry. A descriptive approach to analyse data from an oyster survey was chosen to generate primary information about Australian SRO farmers.

The findings of this study suggest that the majority of SRO growers are male, Australian born and the first generation in their family in oyster farming. A large number of farmers in this industry are of pre-retirement or retirement age. This suggests that oyster farmers have likely gained experience in different professions before becoming an oyster farmer. This finding is supported by the relatively high proportion of current oyster farmers with tertiary qualifications. The relatively low proportion of income generated from oyster farming implies that oyster farming may not be a full-time activity for the majority of growers. This also endorses previous industry statistics that this industry is dominated by small-scale businesses. The aging farmer population and the low number of young oyster growers present in the industry raises the question about potential industry entry barriers. It is unclear why the industry appears to be unappealing for young people. Is it the demanding physical work and the relatively low return from oyster production? Is it the presence of alternative employment offered in other industries or a lack of access to capital? If there is a lack of access to capital, the question arises if there are there alternative lending schemes available from banking institutions that are more focussed on small- and medium businesses in contrast to lending schemes offered by the large commercial banks in Australia. These questions need to be investigated as prerequisite to attracting young people to the industry.

Given the current age structure of the SRO industry members and the present part-time approach to oyster farming their ability to drive innovation and their translations into industry practise as well as willingness to co-operate with research institutions may be compromised and, hence, may hamper future industry development.

The study also provides evidence that oyster farmers have a relatively pessimistic opinion about the future of the industry and that growers are much divided about the introduction of Pacific oyster varieties in NSW and QLD.

The findings of the study suggest that socio-economic characteristics of the SRO growers may contribute to the current decline in SRO production. The future development of this industry will therefore also depend on the ability of the industry management to address the socio-economic issues present in this industry.

In summary, this study has demonstrated by example of Australia's SRO industry, that research into the socioeconomic characteristics in fishery and aquaculture industries can provide industry managers valuable information about the state of the industry and can be used for developing informed industry development strategies.

Acknowledgements. The authors would like to acknowledge the financial support of the Fisheries Research Development Cooperation (FRDC) under the FRDC-funded project 2008/306: "Building economic capability to improve the management of marine resources in Australia". Further financial support was provided by Queensland University of Technology (QUT) and in-kind for this work was provided by the Commonwealth Scientific and Industrial Research Organisation (CSIRO). The authors are particularly grateful to the New South Wales Department of Primary Industries and the Queensland Department for Agriculture, Fisheries and forestry for providing inkind support in the preparation and distribution of an oyster farm survey.

\section{Appendix}

\section{Selected responses from farmers about future prospects of the Sydney rock oyster (SRO) industry}

\section{Income and costs}

"A gradual decline as profitability declines. This decline could accelerate if environmental factors worsen".

"The SRO is a great product but with costs, Fisheries, Food Authority, local government, lands department plus processors slow paying or not paying at all doesn't help”.

"Farmers are walking away because of high fees and charges for small operators”. 
"Under current industry management the seafood fees are astronomical and with more regulations make the oyster industry unattractive to new investors, also the product is only available for a few months of the year".

\section{SRO versus Pacific oyster}

"I think the SRO industry will slowly die due to the Pacific oyster taking an ever increasing market share. The SRO may become the truffle of the sea, scarce and expensive".

"Good, if they can keep the Pacific oysters out. The taste of SRO is much better that is what you get from customers. Commercially, the Pacific oysters are much more attractive. If the Pacific oyster is brought in on larger scale, SRO will vanish slowly".

\section{Technical need and advance related to oyster nursery}

"Access and supply to hatchery stock is an issue, demand is there and increasing, issues come from rain/closures".

"Something needs to be done for farmers to get better and quicker information, too much red tape".

\section{Domestic market and export}

"Limited information available on consumer demand/possible prices as processors are in the way, something needs to be done on the marketing of the $S R O$, the $S R O$ is premium product, industry is divided about marketing of the product, water quality is an issues that may limit production in future, high potential for export of live product into wealthy developing countries such as China / Dubai”.

"Due to limited harvest times (4 months only) buyers want continuity of supply all year round, cannot do this with rocks only”.

"I think the industry will boom with export markets".

"Industry is going through a tough period due to several years of heavy rain. Price needs to be increased, one option could by through exporting oysters".

\section{General industry prospects}

"With research and some assistance from state government the prospects could be very good”.

"Prospects good if water quality can be maintained. Diversity of culture species. Lack of will and ineffective management of catchment areas by Gold Coast City council $\mathcal{E}$ State and Federal Environmental Departments to oversee proposed and existing risks, more about being seen to be 'in control' than being in control".

"The labour intensity of the industry makes the business unviable. A 4 year growing period is twice that of Pacific oysters".

"Enhanced disease prevention and management, greater availability of affordable, high quality hatchery seed, greater emphasis on the importance of local ecosystem conservation [...]. The industry is not doing too well at the moment with the flood events up in the northern estuaries but with a bit of fresh wind and enthusiasm that can be changed".

"NSW and the eastern seaboard have experience the wettest period in a long time. Hopefully the industry as a whole will be boasted in production and management in future. Administrative costs are high and increasing. It is difficult for farmers to find markets at which they can get a good price. Cooperative systems of marketing did not work before so prospects are not good".

\section{References}

ABS, 2012a. Australian social trends: Australian farming and farmers. Canberra, Australian Bureau of Statistics.

ABS, 2012b. Education and work. Canberra, Australian Bureau of Statistics.

ABS, 2013a. 2011 Census QuickStat: All usual residents. Canberra, Australian Bureau of Statistics.

ABS, 2013b. Household income and income distribution, Australia, 2011-2012 Canberra, Australian Bureau of Statistics.

Australian Taxation Office, 2013, Tax Withheld Calculator Individual non-business. Canberra, Commonwealth of Australia.

Cary J., Webb T., Barr N., 2002. Understanding landholder's capacity to change to sustainable practices: Insights about practice adoption and social capacity for change, Canberra: Bureau of Rural Sciences.

Girard S., Pérez Agúndez J.A., 2014. The effects of the oyster mortality crisis on the economics of the shellfish farming sector: Preliminary review and prospects from a case study in MarennesOleron Bay (France). Mar. Policy 48, 142-151.

Jobber D., O'Reilly D., 1996. Industrial mail surveys: techniques for inducing response. Market. Intell. Plann. 14, 29-34.

Leith P.B., Haward M., 2010. Climate change adaptation in the Australian edible oyster industry: An analysis of policy and practice, University of Tasmania, Hobart, Tasmania.

Nossal K., Sheng Y., 2010. Productivity growth: Trends, drivers and opportunities for broadacre and dairy industries. Australian Commodities 17, 216-230.

NSW DPI, 2003. Aquaculture production report 2001-2002. In: Macdonald I. (Ed.). Port Stephens, New South Wales Department of Primary Industries.

NSW DPI, 2013. Aquaculture production report 2011-2012. In: Livingstone S. (Ed.). Port Stephens, New South Wales Department of Primary Industries.

Pascoe S., Cannard T., Jebreen E., Dichmont C., Schirmer J., 2014. Satisfaction with fishing and the desire to leave. Ambio 1-11.

Productivity Commission, 2005. Trends in Australian agriculture, Canberra, Australian Government Productivity Commission.

Schrobback P., Pascoe S., Coglan L., 2014. History, status and future of Australia's native Sydney rock oyster industry. Aquat. Living Resour. 27, 153-165.

Tzanatos E., Dimitriou E., Papaharisis L., Roussi A., Somarakis S., Koutsikopoulos C., 2006. Principal socio-economic characteristics of the Greek small-scale coastal fishermen. Ocean Coast. Manage. 49, 511-527. 